\title{
UNDERSTANDING THE DYNAMICS OF THE UPTAKE OF MATERNAL HEALTH SERVICES IN KEBBI STATE USING A SYSTEMS THINKING APPROACH
}

\author{
Musa Asta ${ }^{1} \boldsymbol{U}$, Mathias Fonkam ${ }^{2}$, Nehemiah Danjuma ${ }^{3}$, Abubakar Attahiru Kaoje ${ }^{4}$, \\ Abubakar Muhammad 5 \\ ${ }^{1}$ EU-MNCHN Project, Kebbi State, UNICEF, Nigeria \\ 2 Department of SCIT, American University of Nigeria \\ ${ }^{3}$ Sokoto Field Office, UNICEF, Nigeria \\ ${ }^{4}$ Office of the Executive Secretary, Kebbi State Primary Health Care Development Agency, Nigeria \\ ${ }^{5}$ Department of Planning Research \& Statistics, Kebbi State Primary Health Care Development \\ Agency, Nigeria
}

DOI: https://doi.org/10.29121/granthaalayah.v8.i7.2020.589

Article Type: Research Article

Article Citation: Musa Asta,

Mathias Fonkam, Nehemiah

Danjuma, Abubakar Attahiru Kaoje, and Abubakar Muhammad. (2020).

UNDERSTANDING THE DYNAMICS

OF THE UPTAKE OF MATERNAL

HEALTH SERVICES IN KEBBI STATE USING A SYSTEMS THINKING

APPROACH. International Journal of Research -GRANTHAALAYAH, 8(7), 318-329.

https://doi.org/10.29121/granthaa layah.v8.i7.2020.589

Received Date: 27 June 2020

Accepted Date: 31 July 2020

Keywords:

System Dynamics

Causal

Effect

Maternal

Loop

Health

Model

Stock

\section{ABSTRACT}

This study focused on the dynamics of Maternal Health Services utilization in Kebbi State using a Systems Thinking approach. The broad objective was to understand the effect of interventions intended to promote utilization of Maternal Health Services. The study evolved a model to represent the causal interrelationship, interdependencies and feedback influences of the multifactorial and multisectoral public health approach on utilization of public maternal health services using a Systems Thinking approach. This enabled us draw inferences on the effect on the mother, the intended end-beneficiary from these interventions. Using a Causal Loop Diagram, we were able to identify reinforcing and balancing feedback loops that could explain the behavior or outcomes being observed. The findings revealed that the feedback in the system is driven by limited resources at the household levels, technical quality of health care services, and knowledgeableness of women on maternal health services. From this, we were able to recommend that policy-makers should try to effectively address socio-economic inadequacies at the household level including socio-cultural practices leading to low level of girl-child school enrolment, and several factors affecting motivation of health care workers. While efforts to ensure quality of care and community awareness should be maintained, emphasis and priority needs to be given to interventions that target economic improvements of households. 

Approach

\section{INTRODUCTION}

The term maternal is used to describe Women of Child Bearing Age (WCBA) universally given as 13 - 50 years old. Maternal Mortality Ratio (MMR) is the annual deaths of females per 100,000 live births from any causative factor that is related to or worsened by pregnancy or its management (not including accidental or incidental causes). The MMR includes deaths in pregnancy, childbirth, or within 42 days of termination of pregnancy, irrespective of the duration and site of the pregnancy, for a specified year (The World Bank Maternal Mortality Ratio).

Maternal mortality has remained unacceptably high globally with most of the deaths occurring due to preventable causes. An estimated 830 women die every day while $99 \%$ of the annual maternal deaths occur in Lowand Middle- Income countries. Nigeria records one of the highest Maternal Mortality Ratios in the world, accounting for $10 \%$ of all maternal deaths in the world. The figures are even more worrisome in North-West Nigeria, with a maternal mortality ratio of 1,549 deaths per 100,000 live births (National Population Commission, International. Nigeria Demographic and Health Survey Preliminary Report 2013). Several surveys have shown that MMR is highest among women who are non-literate and live in rural communities that are considered poor.

The global Maternal Mortality Rate has been reduced by 44\% between 1990 and 2015 (The World Health Organization Fact Sheet, 2019) as a result of multi-sector collaborative actions and the global drive through the Millennium Development Goals (MDG) initiative. The eventual Sustainable Development Goals have set a target to reduce maternal mortality ratio to less than 70 per 100,000 Live Births between 2016 and 2030.

The leading direct causes of maternal mortalities, accounting for about $75 \%$ of deaths, as reported by the WHO are severe bleeding, infections, high blood pressure during pregnancy, complications from delivery and unsafe abortion. Accessibility to needed care (such as Antenatal care, delivery by skilled personnel, postnatal care and postabortion care) is fraught with inadequate maternal health care services, and poor uptake of services due to location inaccessibility, poverty, cultural beliefs and lack of information, among others.

To address these mortalities, the first step is to deploy tools that provide an understanding of the complexity of the factors that cause inaccessibility to quality health care services so as to recognize how their interactions influence other variables within the same system. To achieve the target of the Sustainable Development Goals (SDGs), it is herein emphasized that health system stakeholders across all levels should employ the use of numerous best practices to gain deeper understanding of the interdependencies and interactions between and amongst the factors that have inhibited the achievement of past goals. Additionally, these practices will provide a basis to appreciate the unintended impact of multisectoral, multiapproach on the pregnant woman or mother, who's live is being saved. The purpose is to enable policy makers identify where high-leverage intervention points may lie which will lead to maximum overall gains and this inference is used to inform formulation of effective policies and intervention strategies that will lead to the intended outcomes. One of these best practices is the use of the Systems Thinking approach for program design, implementation, evaluation and learning.

\subsection{STATEMENT OF THE PROBLEM}

Adequate maternal health services have been found to be paramount in saving the lives of women who otherwise might die due to pregnancy-related, child-birth and puerperal complications. The health systems of most developing countries have been unable to deliver adequate care to the women who need it most. Despite the investments in diverse strategies over time, to improve essential lifesaving health services and health outcomes, utilizations have remained significantly low, the UNICEF Multiple Indicator Cluster Survey (MICS) showed that in 2017 , only $17.9 \%$ of deliveries were conducted by skilled personnel, about $12.2 \%$ of expected deliveries were institutional deliveries, only about $20.9 \%$ of pregnant women completed the recommended four Ante Natal Care (ANC) visits and $11.7 \%$ of mother and child pair received immediate postnatal care. Similarly, the National Demographic Health Survey (NDHS) reports show an average uptake of skilled assistance at birth at a rate of $13.4 \%$ between 2003 to 2018 with the lowest rate recorded in 2008 at 9.8\%, the highest recorded in 2018 at $19.0 \%$, and same rates recorded in 2003 and 2013 at $12.3 \%$. The challenge to effectively overcome under-utilization of primary health care services may be attributed to limited knowledge of the complex interplay within the health system and their internal interdependencies, leading to unexplored leverage opportunities which could have led to optimized gains from the strategies implemented. 


\subsection{AIM AND OBJECTIVE OF THE PAPER}

The aim of the study is to understand the complexity of the health system in Nigeria. The objectives are:

1) To apply the systems thinking approach methodology to understand issues surrounding maternal health in Kebbi state Nigeria.

2) To understand dynamics of health service utilization by pregnant women in Kebbi State Nigeria.

3) To explore intervention measures that actually could lead to an improvement in maternal service uptake in public health facilities in Kebbi state Nigeria.

\section{LITERATURE REVIEW}

System Dynamics extends systems thinking with a computer simulation methodology useful for unveiling the dynamic complexity that all too often characterizes nonlinear human systems. Systems thinking embodies a paradigmatic shift from a reductionist view of problems as made of parts that can be independently handled and summed up for a solution to the whole, to a holistic view where the behavior of the whole is seen as emerging from the interactions of the parts (Rahim, Hawari and Abidin,2017). A system is therefore seen from this perspective to be a product of the interaction of its parts rather than the sum of their outputs as the reductionist view assumes. The systems approach comes with a graphical (a picture is worth a thousand words!) language for modeling and depicting both the system structure and the resultant behavior produced from interaction of the parts of that structure. Structure modeling techniques include causal loop diagrams, stock and flow models and rich-picture models while behavior over time graphs are the main vehicle for depicting and communicating system behavior. Principle components of system structure for dynamic systems are stocks, flows, time delays, and overarching feedback loops that interconnect stocks with the flows that feed and deplete stocks (Rahim, Hawari and Abidin,2017).

Karl Ludwig von Bertalanffy, an Austrian biologist, and one of the earliest voices in the field, established general system theory as a multidisciplinary subject with cross-cutting concerns and a set of concepts, principles and mechanisms that could be applied across disciplines. He argued that Systems Thinking cannot be traced to any one discipline, rather the leading theories can be traced to different disciplines. It was initially called General systems theory; a meta-theory which means a theory of theories. It has been used in various fields to gain deeper understanding of complex systems. Systems Thinking is the new way of thinking when dealing with complex problems in today's ever-changing world. (Bogdanov, Alexander 1996)
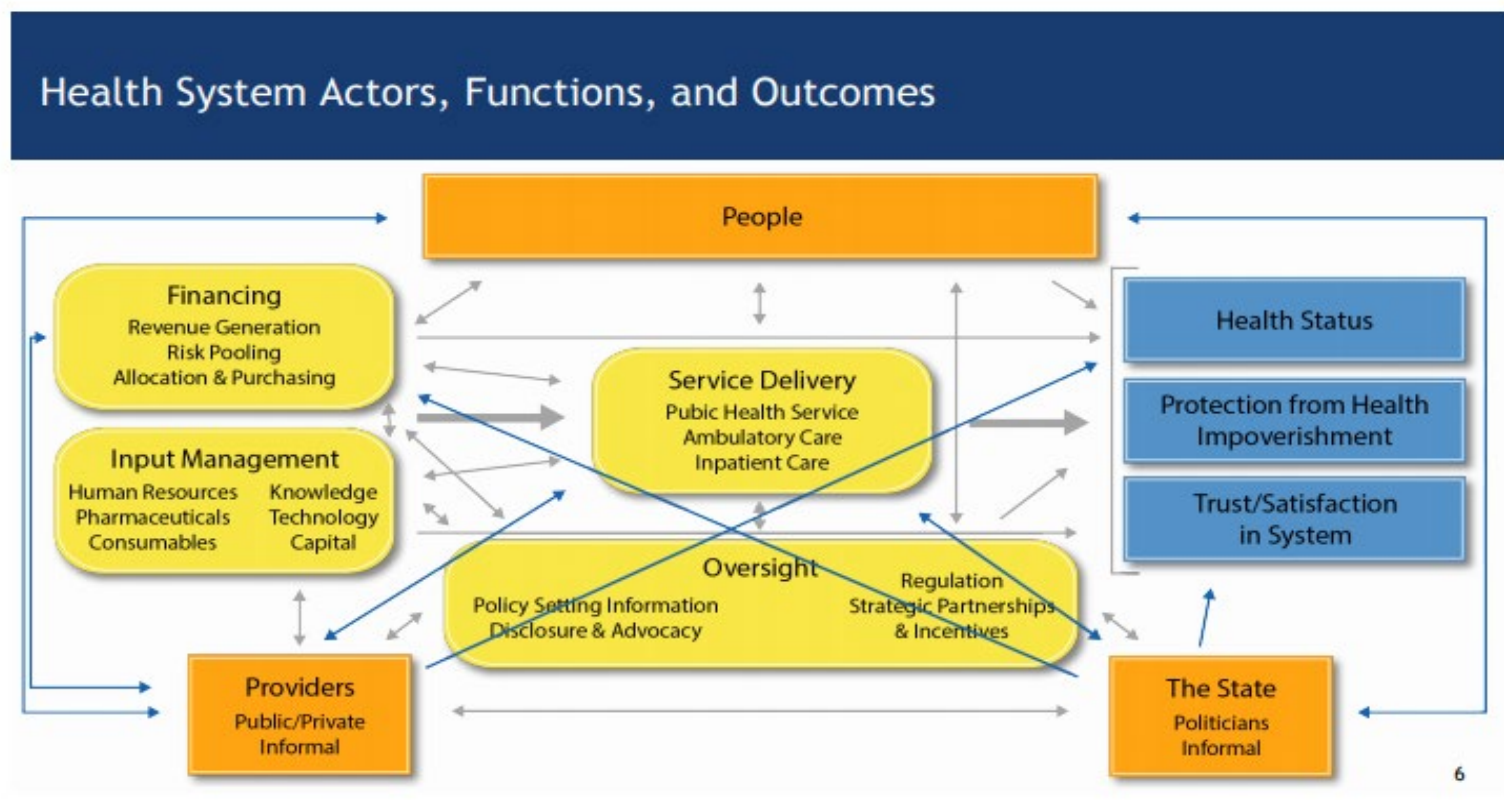

Figure 1: Health System Application of CAS. source: adapted from Systems Thinking in Public Health module, John Hopkins School of Public Health(Basole and Rouse, 2008; Martínez-García, 2013). 

Approach

The study of complex systems has progressed across multiple disciplines, figure 1 above gives a model of a Complex Health System. This progress in research streams over time forms an overlapping set of sciences with a common philosophical basis with emphasis being placed on the relationships between the parts that form the system in addition to understanding the individual parts and their environment separately (Castellani, 2014). The following compendium of reviewed literature studies how public health specialists have employed the use of System's Thinking approach to study the complex health system. Although several research has been done to study how System's Thinking is applied to understand system behavior that advances or hinders attainment of the global vision for Universal Health Coverage, uncharted research area is how multi-sectoral factors and policies that target enduser beneficiaries may interplay and inter-relate to produce an undesired systemic behavior, particularly in lowresource settings.

Hernández, Ruano, Marchal, Sebastián \& Flores (2017) in their article "Engaging with complexity to improve the health of indigenous people" called for the use of Systems Thinking to tackle health inequity. They argued that to achieve the Sustainable Development Goals (SDGs) of Universal Health Coverage (UHC) and promote sustainable development, there is need to move beyond the reductionist tendency and adopt a Systems Thinking approach which targets service delivery tactics and move towards holistic, integrated approaches that address the causes of inequalities both inside and outside the health sector. According to the authors, applying Systems Thinking approaches gives better understanding of the evolution of equity-oriented research and practice in collaborative, politically informed and mutually enhancing efforts to understand and bring about changes in the systems that leads to inequities in indigenous health.

Roux, (2011) in his study "Complex Systems Thinking and Current Impasses in Health Disparities" research argued that the field of health disparities can move forward through the use of Systems Thinking in 3 ways: (1) Systems Thinking promote the development of more sophisticated dynamic conceptual models of the causes of health disparities, (2) systems tools (formal models and simulation) help explore and refine these models and explore the effects of different interventions in the context of dynamic relations, and (3) the use of systems approaches to enhance the use of existing data and promote the collection of new types of needed data. He therefore concluded that the use of Systems Thinking can help researchers get beyond the current impasse point in health disparities research.

Cameron, Norman, Charnaw-Burger, Yip, Saad, \& Lombardo, (2010) conducted a study on Designing health innovation networks using complexity science and Systems Thinking using the Complex Network Electronic Knowledge Translation Research CoNEKTR model. The researchers noted that complex problems require strategies to engage diverse perspectives in a focused, flexible manner, yet few options exist that fit with the current health care and public health system constraints. The CoNEKTR model brings together complexity science, design thinking, social learning theories, Systems Thinking and eHealth technologies together to support a sustained engagement strategy for social innovation support and enhancing knowledge integration. The CoNEKTR model was used as a tool in Systems Thinking, the model adapts elements of other face-to-face social organizing methods and combines it with social media and electronic networking tools to create a strategy to generate ideas, refinement and social action. Using an approach which draws on complexity science, the researchers conducted a series of interacting activities which enhanced dialogue as well; to bring different groups together, bring about dialogue and create network of networks. the model is useful when it comes to enhancing system capacity for knowledge generation, learning and action while working within the confines faced by busy health professionals.

Durham, Schubert, Vaughan, \& Willis (2018) applied System's Thinking to understand systemic factors that generate prevalence of Otitis Media infection among a target population in Australia. The focus of this study is to understand the interactions among an internal set of factors, including policies and other social determinants, that cause susceptibility of Otitis Media (Middle Ear Infection) among Aborginal and Torres Strait Islander Children. He used Systems Thinking and the Intervention Level Framework (ILF) to analyze public health planning for complex problems with emphasis on Otitis media in Aboriginal and Torres Strait Islander children in Australia. They argued that Systems Thinking is the best a way to understand and tackle complex public health issues such as obesity, tobacco control, antibiotic resistance, and the social determinants of health, thus informing their choice of the use of Systems Thinking approach. Their study aimed at identifying which combination of activities, and at which level, held the potential to facilitate systems changes to better support ear health among Aboriginal and Torres Strait Islander children. The Intervention-Level Framework (ILF) as A System Thinking tool was used. Data was collected through review of identified documents in consultation with stakeholders, qualitative interviews were also 
Musa Asta, Mathias Fonkam, Nehemiah Danjuma, Abubakar Attahiru Kaoje, and Abubakar Muhammad

conducted to elicit a diverse range of views. Thoughts, statements or events stated in the documents and interviews as being done under the Intervention Level Framework were identified by the use of qualitative thematic and content analysis. Activities were then coded against the five-level intervention framework namely (1) paradigm; (2) goals; (3) system structure; (4) feedback and delays; and (5) structural elements. The result of the study revealed that most of the activities fall in the structural element category. suggesting that governance structures for multi-sectoral collaboration including the development of joint goals and monitoring and feedback are required. Intervening at these higher leverage points could have a better effect on persistent public health issues.

Mutale, Ayles, Bond, Chintu, Chilengi, Mwanamwenge, Taylor, Spicer and Balabanova (2015) Used Systems Thinking to conduct a 12-month postintervention evaluation of a complex health system intervention in Zambia using Better Health Outcome through Mentorship and Assessment (BHOMA) intervention as their case study. Here, System's Thinking was deployed to understand the interaction of factors, given a specific set of predetermined interventions, responsible for generating the system behavior over time. They acknowledged that managers and policy makers could benefit from understanding the importance of Systems Thinking and the complex behaviour of systems, therefore they used Systems-Thinking guided analysis framework based on the six building block of the health system as a tool to collect qualitative data through interviews and focused group discussions with health workers and community members in communities where the BHOMA interventions were carried out. The findings of the study, which was depicted in a causal loop diagram, showed that the intervention improved the quality of services in the health facilities. However, through the use of System Thinking, unintended consequences of the intervention were noted alongside other contextual factors that seemed to have had an interplay with the intervention thereby altering the effects of the intervention.

Bishai, Paina, Li, Peters, and Hyder (2014) conducted a study on advancing the application of Systems Thinking in health: Why cure crowds out prevention. They applied the System's Thinking approach to the area of health care financing with a comparison of funding provisions between curative care interventions and preventive care strategies. This study focuses on the Leadership and Governance component of the Health System, not on Service Delivery and its dynamics. They observed that the model used must be such that will yield identification and understanding of unintended consequences of the complex adaptive system. In view of this, the study employed the principle of system dynamic modelling. The population and disease model were used as a System Thinking tool. Their findings revealed the trade-offs between curative and preventive health allocations, and the effect of indicative policy interventions. The fundamental dynamics of this artificial system is similar to modern health systems where disease-specific curative programs such as malaria are being drowned by self-preserving industries. The model developed illustrates negative feedback growth of curative care services can have on preventive services through undesirable influences on fiscal and policy space.

Achoki and Lesego (2017) carried out research on the imperative for Systems Thinking to promote access to medicines, efficient delivery, and cost-effectiveness when implementing health financing reforms in Botswana. The aim of their study was to determine the potential health systems impacts that would result from the proposed expansion of the public-sector employees' health insurance scheme as a pathway towards UHC in Botswana. They opined that to go in line with Universal Health Coverage, health care financing reforms should not only be viewed in a reductionist way alone but also try to expand effective coverage and improve population health outcomes. They also argued that any health financing restructuring needs to be examined holistically, paying specific attention to the complex relations it has with different components of the broader health system, and how that hinders or enhance progress towards UHC. In view of this, they adopted the framework described by WHO, where the health system is viewed as comprising six discrete pillars (the six-building block of the health system) as a Systems Thinking tool for their research. They employed the Key Informant Interview (KII) approach to collect qualitative data from identified participants. The data collected was analyzed using thematic analysis. Results from the analysis revealed that expansion of health insurance would be characterized by increased financial resources for health and catalyze an upsurge in utilization of health services particularly among those with health insurance cover. As an outcome, the health system, mostly within the private sector, would be likely to see more request for medicines and other health technologies. However, most of those who responded to the questionnaire advised that, understanding the full benefits of improved population health, unbiased supply and financial risk protection, would entirely depend on having good policies, guidelines and functional accountability systems in place. They recommended that decisionmakers goal to achieve universal health coverage must view health financing reform through the holistic lens of the health system and its interactions with the population, in order to anticipate its potential benefits and risks. Failure to make judicious use of this all-inclusive method would potentially lead to results that may be counterproductive. 
While this study focused on financial risk protection gained through user-fee waivers as a strategy to relieve the financial burden of utilizing health care services, the model being tested in our research is suggestive of the limitation of affordable health care services to produce a sustained desirable uptake rate of maternal services among pregnant women and mothers.

Carey, Malbon, Carey, Joyce, Crammond, \& Carey (2015) carried out a systematic review in the field of Systems Science and Systems Thinking for public health. The objectives of their review were to explore how systems methodologies are being applied within public health and identify fruitful areas of activity. The systematic review was done by a literature survey of 117 studies on use of Systems Thinking in various fields like tobacco, alcohol, obesity and social determinants of health. The survey revealed that there is a great deal of interest in how the application of systems concepts and approach might aid public health. They therefore recommended that soft systems modelling techniques are likely to be the most useful addition to public health, and align well with current debate around knowledge transfer and policy.

Homer \& Hirsch (2006) conducted a study on "System Dynamics Modeling for Public Health: Background and Opportunities". They used variables like disease outcomes, health and risk behaviors, environmental factors, and health related resources and delivery systems to model chronic disease prevention the result of which was presented in a causal loop diagram. The use of the systems modeling approach was able to dig out multiple interacting diseases and risks, the interaction of delivery systems and diseased populations, and matters of national and state policy.

To understand the complex dynamics of neonatal mortality in Uganda, Rwashana, Nakubulwa, NakakeetoKijjambu, \& Adam (2014) applied Systems Thinking approach. The objectives of their study were to explore how Systems Thinking tools can help to gain a better understanding of the complex factors that influence neonatal mortality and to identify strategies and leverages that may yield success in fast-tracking progress. Causal Loop Diagrams (CLDs) as a Systems Thinking tool was used in this study to show the interaction and interplay of the variables that contributes to neonatal mortality. These variables were obtained from interviews conducted with various stakeholders including mothers, village health workers, community leaders, front-line health workers and policy/decision makers. Brainstorming sessions were used to develop two CLDs-one showing the demand side factors that causes neonatal mortality and the other showing supply side issues influencing neonatal mortality. Factors such as maternal health, level of awareness of maternal and newborn health, and availability of quality of health service were among other factors identified to be causes of neonatal mortality, the reinforcing and balancing feedback loops that resulted from the interaction of these factors were also examined. They identified potential high leverage points to include special gender consideration to ensure girl-child education thereby increasing maternal literacy rates, improved socioeconomic status that will enable mothers utilize health services, improved supervision as well as addressing human resources gap. They concluded that the use of CLDs as a Systems Thinking tool facilitated better understanding and interpretation of the interactions and feedback loops that contributed to the stagnant neonatal mortality rate. This stagnation is mirrored in the uptake of maternal services in Kebbi State, a necessary determinant for maternal health, despite implementation of interventions derived from the recommendation regarding Girl-Child education, Quality Improvements and bridging Human Resources for Health gaps.

Sarriot, Kauletio, Jahan, Rasul, \& Musha, (2014) carried out a study on advancing the application of Systems Thinking in health using sustainability evaluation of the concern project in northern Bangladesh. They argued that sustainability is dynamic and as such requires both implicit and explicit Systems Thinking steps. This informed their decision to use the sustainability framework method as a Systems Thinking tool to generate creative thinking from stakeholders, create a common vision and monitor progress. Their study revealed that strategic choices for the project were guided by articulating a collective vision for sustainable health, it further revealed that in order to make and sustain change, mapping the system of actors was required. They therefore recommended strengthening functionality of ward health committees and resource leveraging between municipalities and ministry of health.

Peters (2014) in his article on application of Systems Thinking in health gave reasons why Systems Thinking approach is ideal in solving health problems. He argued that the use of Systems Thinking approaches inspires a scientific habit of mind adding that usage of any of the Systems Thinking tool can reinforce militant ignorance as a basis for expanding scientific knowledge. He further argued that Systems Thinking provided new opportunities to better understand the dynamics of the healthcare system hereby having a better knowledge of where and when to intervene in order to attain the greatest impact. 
Sharma \& Matheson (2016) in their article on "Systems Thinking in 21st century: A call to health promoters" acknowledged the complex and multi-factorial issues such as malnutrition, maternal mortality and noncommunicable diseases that are involved in health promotion. They observed that in theory, health promotion uses Systems Thinking in promoting public health but in practice, it is dominated by the reductionist thinking, an approach which according to them have not yielded the desired results as the root causes of public health problems such as poverty, access to quality health services and the empowerment of women still remain unresolved. These unresolved problems call for an alternative approach, the Systems Thinking approach, which is a Systems Sciencebased thinking that could provide appropriate scientific foundation for health promotion discipline to address complex health problems and its root causes. They further argued that Systems Thinking is proving to be a better approach to understanding and dealing with complex public health problems where several factors interact. Just like the popular story of "Five blind men and the perception of the elephant's body", there is need for a comprehensive approach like Systems Thinking that could connect the incorrect mental models of each of the blind men and assist in developing a holistic shape of the elephant that reflects its reality.

Varghese, Kutty, Paina \& Adam (2014) used Systems Thinking in understanding the growing complexity governing immunization services in Kerala, India. Their study was prompted by findings from an earlier study highlighting the need to further explore the complexity of immunization services in Kerala. Qualitative methods were used to explore the factors underlying changes in vaccination coverage in two districts in Kerala, one with high coverage and the other with low coverage. Features associated with complex adaptive systems such as phase transitions, feedback, path dependence, and self-organization were guided by content analysis. Causal loop diagrams were developed to show how several factors and events interacted to bring about changes in vaccination coverage. Findings revealed the various complex adaptive system phenomena that influenced the change in vaccination coverage levels in the two districts. Phase transition shows how accepting vaccination in the early stage was replaced by a non-acceptance in northern Kerala, which brought about new actors' involvement, actors trying to regain acceptability and others who rejected it created several feedback loops. The manner in which the authorities have responded to declining immunization coverage and its impact on vaccine acceptability was also described. Theoretical exposition of these findings revealed the important role of trust in health workers and institutions that shape the interactions of actors leading to complex adaptive system phenomena. The Systems Thinking approach employed in the research assisted the researchers and decision makers to systematically explore the driving forces and factors in each setting and develop appropriate and timely strategies to address them.

The application of systems approach to solve real life problems cannot be overemphasized. On Maternal health issues, researchers have argued and maintained that the essential live-saving maternal health care includes: Antenatal care services, skilled delivery services, post-natal care services and health education and awareness. Uptake of these services vary in the different contexts of countries. In Low- and Middle- income countries where uptake of maternal services is low among rural women, a study by Zaidi et al (2015) on 'the Residual Barriers for Utilization of Maternal and Child Health Services: Community Perceptions From Rural Pakistan' identified some the of barriers as low awareness about importance of care, distance from health facility, inadequate transport, cultural beliefs, among others. The table 1 below shows some key barriers identified in the study.

Table 1: Barrier to Utilization of Maternal care services. source: Zahid Memon Shehla Zaidi and Atif Riaz, 2015 Perceived barriers to utilization of $\mathrm{MCH}$ services

\begin{tabular}{|c|c|c|c|}
\hline \multicolumn{4}{|l|}{ Maternal care } \\
\hline ANC & Facility based delivery & PNC & Maternal complications \\
\hline $\begin{array}{l}\text { - L ack of awareness about } \\
\text { importance of seeking } \\
\text { ANC }\end{array}$ & $\begin{array}{l}\text { - Lack of awareness } \\
\text { about importance of } \\
\text { facility based birth }\end{array}$ & $\begin{array}{l}\text { - Lack of awareness about } \\
\text { importance of seeking PNC }\end{array}$ & $\begin{array}{l}\text {-Unaffordability of } \\
\text { medicines and transport }\end{array}$ \\
\hline - Long distance & $\begin{array}{l}\text {-Unaffordability of } \\
\text { medicines and transport }\end{array}$ & & $\begin{array}{l}\text { - Lack of female staff and } \\
\text { medicines in public } \\
\text { facilities }\end{array}$ \\
\hline -Inadequate transport & $\begin{array}{l}\text { - Fear of Caesarian } \\
\text { Section and vaginal } \\
\text { examination }\end{array}$ & & $\begin{array}{l}\text {-Poorly functional public } \\
\text { sector facilities }\end{array}$ \\
\hline $\begin{array}{l}\text { - Lack of female staff in } \\
\text { public facilities }\end{array}$ & $\begin{array}{l}\text {-Difficult physical } \\
\text { access }\end{array}$ & & -Inadequate transport \\
\hline $\begin{array}{l}\text {-Poorly functional public } \\
\text { sector facilities }\end{array}$ & $\begin{array}{l}\text { - Lack of female staff in } \\
\text { public facilities }\end{array}$ & & \\
\hline -Unaffordability & $\begin{array}{l}\text {-Poorly functional } \\
\text { public sector facilities }\end{array}$ & & \\
\hline $\begin{array}{l}\text { - Limited mobility of } \\
\text { women and security } \\
\text { concerns }\end{array}$ & $\begin{array}{l}\text { - Limited mobility of } \\
\text { women and security } \\
\text { concerns }\end{array}$ & & \\
\hline -Cultural Issues & & & \\
\hline
\end{tabular}




\section{RESEARCH METHODOLOGY}

The study is focused on the health system in Kebbi State relating to maternal health. The targeted population for this study is women of child-bearing age having an estimated population of 996,848 as at 2017 in 225 PHC centers across the 225 political wards. (National Population Council, Kebbi State)

\subsection{DATA COLLECTION}

Data for the study was obtained from secondary sources and a Focused Group Workshop. The secondary sources include UNICEF 2017 MICS Report, World Health Organization 2018 Health Reports and factsheets, research by Zaidi et al (2015) on 'the Residual Barriers for Utilization of Maternal and Child Health Services: Community Perceptions from Rural Pakistan', Kebbi State Ministry of Health, Kebbi State Primary Health Care Development Agency and Kebbi State Population Commission.

Qualitative method was used to collect data through an Empirical Literature investigation and Participatory Iterative Development Process involving stakeholders in a focused group discussion. Empirical Literature review was employed to ascertain factors that cause inaccessibility to quality maternal health services, recurring systemic issues in public maternal health and the recommended high-impact interventions. A Simplified Variable Elicitation Script was used in a Participatory Iterative Development process involving key stakeholders to elicit and validate these factors, to iterate the presence of high-impact interventions in the state, and to explore the perceived causal relationships and interactions among these factors, in the Kebbi state context.

Kebbi State Primary Health Care Development Agency was instrumental in the coordination of implementing partners, community representatives and Ministry of Health for validation of variables and their interactions.

\subsection{METHOD OF DATA ANALYSIS}

A consensus building approach (also called Collaborative Problem Solving) was used to conceptualize and validate variables and the causal relationship between elements of the system. This approach was deployed as an effective tool for mediation of varying perceptions which involves multiple complex issues (as recommended by the University of Colarado OTPIC Program, 2019). Vensim ${ }^{\circledR}$ software was used to draw the Stock \& Flow and Causal Loop Diagram (CLD) used to depict the causal relationship between the validated variables within the predetermined boundaries of the health system, as shown below.

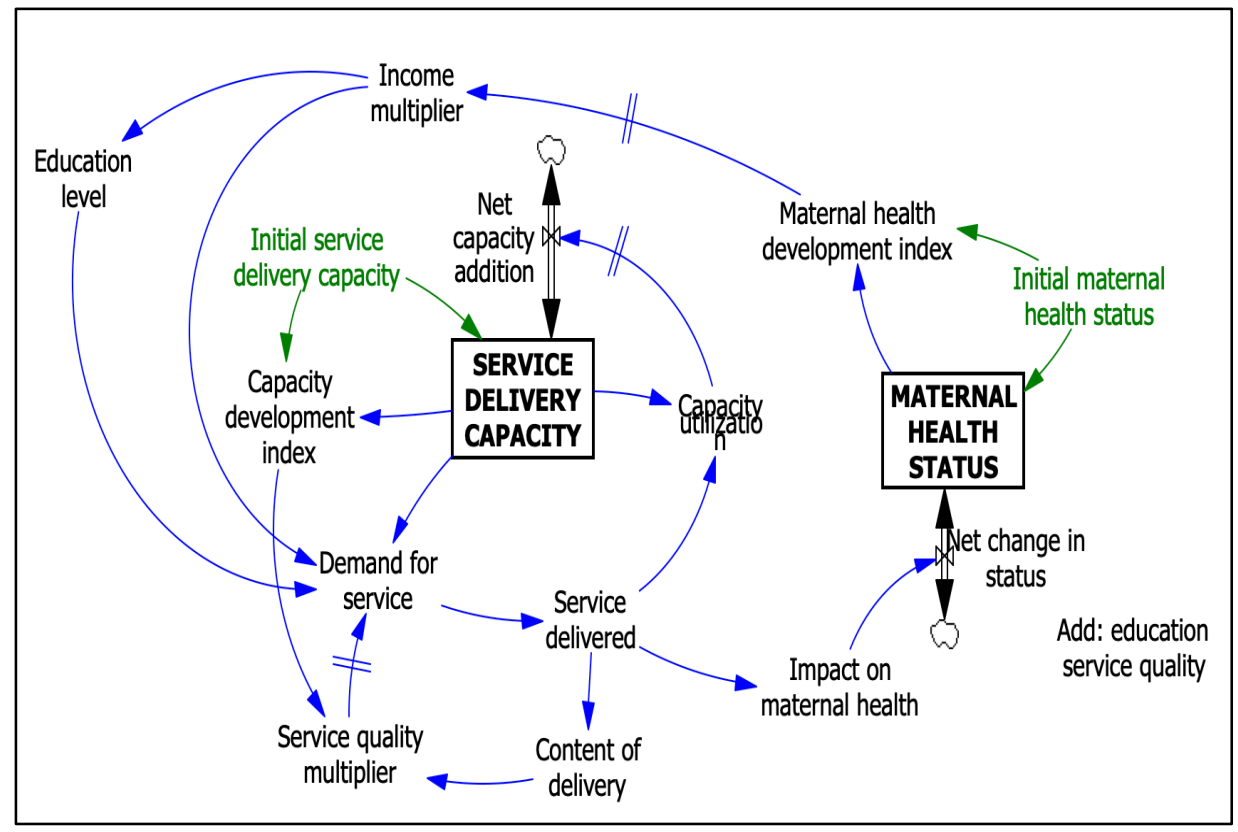

Figure 2: Stocks and Flow diagram of Maternal Service Uptake in Kebbi State 


\subsection{RESULTS AND DISCUSSION}

A causal loop diagram was developed depicting the range of factors associated with uptake of maternal health care services at public health facilities, in Kebbi state. These factors included:

1) knowledge \& awareness of mothers

2) quality of maternal care services

3) healthcare workers motivation and workload

4) household disposable income

5) cost of health services for other diseases

6) user fee waiver and other uptake incentives

7) social mobilization and campaigns

8) mother's health and well-being

9) socio-cultural practices

10) maternal literacy

11) mother's income

The reinforcing and balancing feedback loops associated with the complex system were identified and studied. High-impact leverage points include interventions that target socio-economic empowerment of households/mothers, sustaining health workforce and capacity, and sustained community awareness interventions targeting knowledge of mothers.

Livelihood outcome areas such as school enrolment especially for girl child, uptake of maternal services, uptake of other health services, food and shelter, etc. all compete for limited resources in the households. The interventions driving specific program outcomes targeting the same household interrelate to cause a short-term and long-term threat to household disposable income, as a result the causal loop diagram depicts an overall balancing effect where utilization, quality of services and household income are maintained at an equilibrium. Recently, Organizations in an effort to improve impact are continuously integrating to implement as a single front to eliminate wastages and duplications. This approach is effective for reducing the cost of implementation; however, this may not impact on uptake of services.

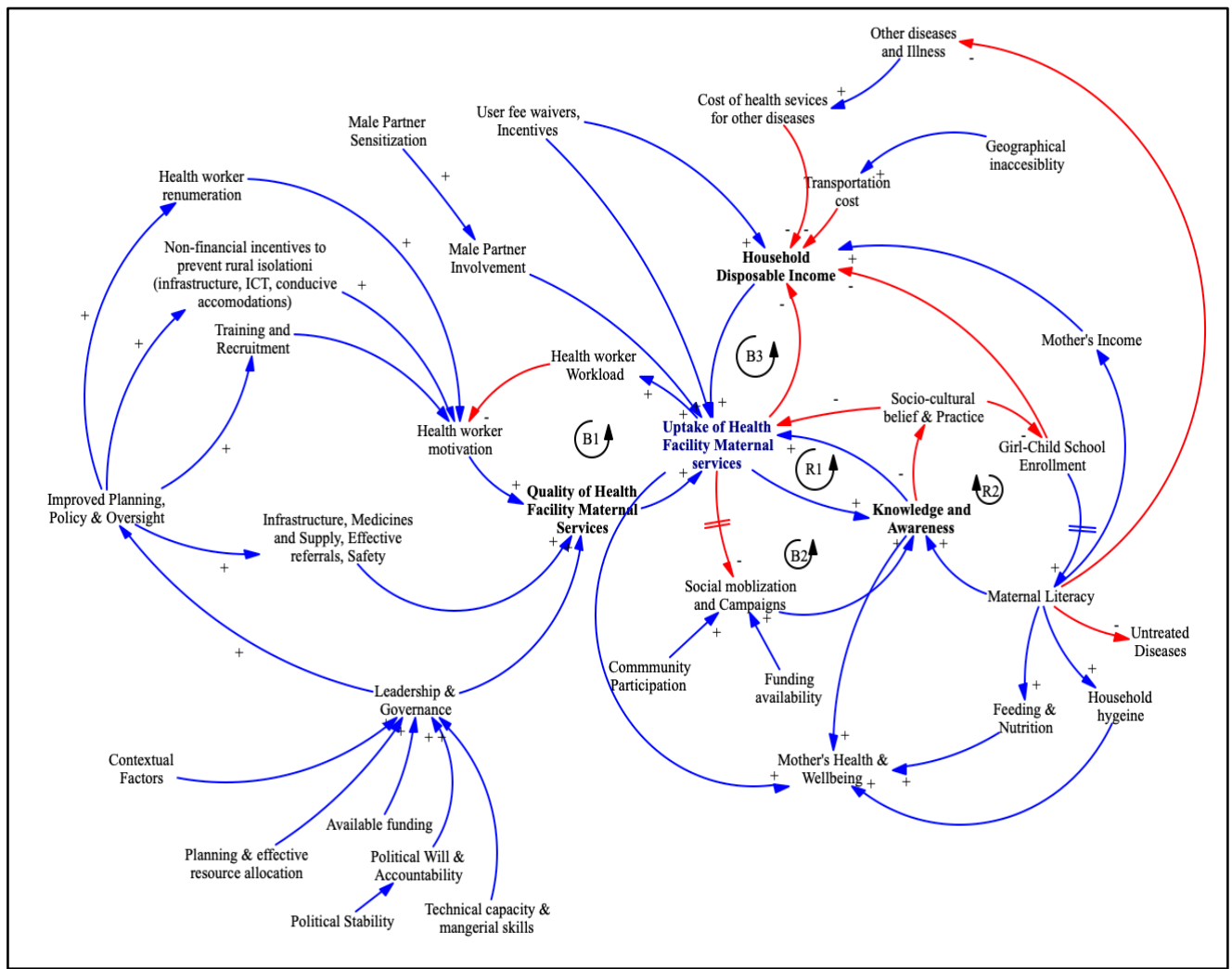




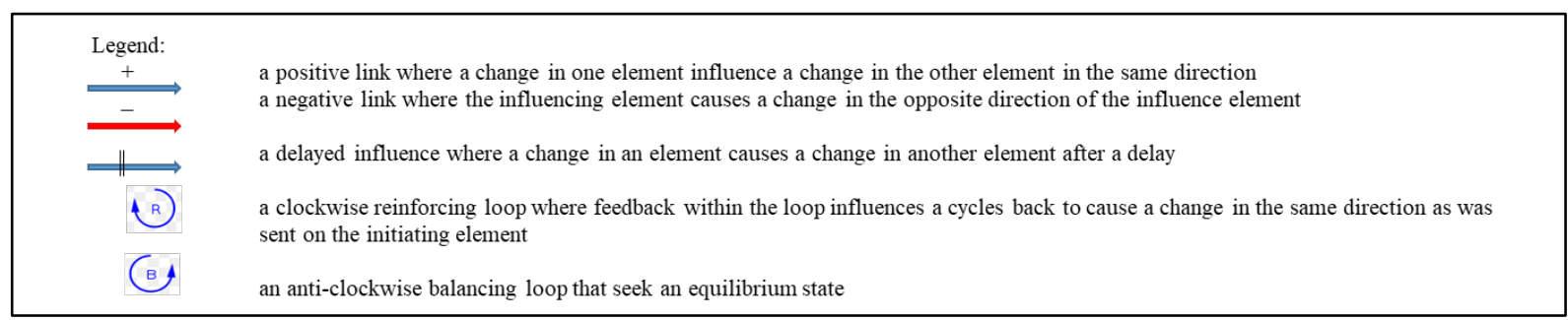

Figure 2: Causal Loop Diagram on Uptake of maternal health services in Kebbi State

R1 loop has a reinforcing effect between knowledge of mothers and uptake of services. The more aware and knowledgeable mothers are on the importance of maternal health services, the more uptake of this service will improve, in turn, the more mothers receive maternal health services the more their knowledge improves - a virtuous cycle. R2 is the second reinforcing loop identified in the system above, this loop is the maternal literacy loop. The more female children are enrolled in school, the more mothers will become literate over time. When maternal literacy improves, knowledge \& awareness on maternal health will improve, this will lead to a reduced reliance of harmful cultural practices - including those that restrict women from education. This will in turn lead to an increase in girl-child enrollment which cycles back to form another virtuous cycle.

B1, B2 and B3 are balancing loops that show the balancing effect of health worker workload on uptake of maternal health services, effect of social mobilization on uptake of maternal services and effect of limited household income on uptake of maternal services, respectively. The B1 loop show that when quality of services is adequate it will lead to an increase in uptake of services, this will then be led to increase workload which in turn affects health worker motivation negatively, health worker motivation influences quality in the same direction. The B2 loop show that effective social mobilization \& campaign activities will lead to increased knowledge of mothers which will lead to an increase in uptake of maternal services, this will in turn lead to a decrease in social mobilization campaigns over time due to depleted sense of urgency brought about by increased uptake. The B3 loop show the balancing effect between availability of household disposable income with uptake of health services.

This study shows that utilization of maternal health care services in Kebbi State is maintained at a state of equilibrium resulting from the feedbacks between the key players - health workforce and the quality of services they provide, knowledge \& awareness of mothers, and availability of disposable income in the households. This is in agreement with the studies conducted by Rashwana et al, (2014) in Uganda on modelling the dynamic of maternal health. The balancing effect between utilization and quality of maternal health services achieved through an increased volume of services leading to increased workload of staff which has a negative impact on the quality of services they provide. This study also found the effect of poverty (using household disposable income as the proxy) on utilization of maternal health services. Limited resources in the household are competed for by numerous basic demands, and often the opportunity cost lead to a stringent scale of preference where minor illness or 'check ups' is not prioritized. Presence of alternative health services and its patronage also reduces the need to access health facility maternal services by rural women. As found by the study in Uganda Rashwana et al, (2014), the causal loop shows quality of Leadership \& Governance as key variable to maintaining the required motivation of health workforce and their adequacy for sustaining a level of quality of care.

\subsection{SUMMARY}

A Systems Thinking approach was employed to understand the inter-dependencies and interrelationship among recurring systemic issues influencing maternal health care service uptake in Kebbi State. A literature review was conducted to deduce these systemic issues in public maternal health, including the recommended high impact interventions which have been adapted to suit conceptual factors and are being implemented in most low- and middle-income countries. A Causal Loop Diagram was used to depict the interrelationships among elements of the complex system, analyze areas of reinforcing and balancing feedbacks, and to identify high-impact leverage opportunities that can lead to maximum outcomes. The findings revealed that the feedback in the system is driven by limited resources at the household levels, technical quality of health care services, and knowledge of women on importance of maternal health services. These three factors are drivers of the system behavior with Disposable Household Income in the lead. Therefore, the highest leverage point lies at household disposable income point, and 
interventions that target economic empowerments should prioritized in Kebbi State. These interventions must go beyond the national policies for financial protection, i.e. National Health Insurance Scheme and Basic Health Care Provision Fund. Gainful employment opportunities must be prioritized, including Economic Empowerment Programs such as Skill Acquisition programs and Entrepreneurship.

\section{CONCLUSION}

To achieve the SDG goal of reducing maternal mortality to 70 per 100,000 live births by 2030 , actors in the health system must recognize the complexity emerging and dynamic nature of the health system and to situate adequate response. A deeper understanding of the holistic system and its interplay becomes crucial in order to respond effectively to the recurring issues which makes it close-to-impossible to significantly address preventable deaths of mothers. Systems Thinking avails the opportunity for this understanding, it further allows the opportunity for modelling our perception of the system and testing areas of interventions so as to see what outcomes they will yield, that is intended and unintended outcomes. To achieve the desired uptake level among pregnant women and nursing mothers, economic empowerment of households and women is vital.

\subsection{RECOMMENDATIONS}

Policy-makers must plan to effectively address socio-economic inadequacies at the household level, by implementing strategies which focus on providing fundamental solutions, in a manner that is sustainable. Additionally, Health Care managers must effectively deploy adequate managerial skills to ensure quality services are consistently provided at public health facilities. While current and upcoming efforts to ensure quality of care and community awareness should be maintained/encouraged, emphasis and priority needs to be given to interventions that target economic improvements of households.

An in-depth analysis should be conducted to identify additional factors influencing maternal health outcomes in Kebbi State.

\subsection{FURTHER STUDIES}

Further studies should be carried out to explore potential strategies for improving maternal health outcomes, using the Systems Thinking approach and its tools on a wider scale.

\section{SOURCES OF FUNDING}

This research received no specific grant from any funding agency in the public, commercial, or not-for-profit sectors.

\section{CONFLICT OF INTEREST}

The author have declared that no competing interests exist.

\section{ACKNOWLEDGMENT}

None.

\section{REFERENCES}

[1] Achoki, T. and Lesego, A. (2017). The imperative for Systems Thinking to promote access to medicines, efficient delivery, and cost-effectiveness when implementing health financing reforms: a qualitative study. International Journal for Equity in Health, 16(53). 
Understanding the Dynamics of the Uptake of Maternal Health Services in Kebbi State Using a Systems Thinking Approach

[2] Basole, R.C. and Rouse, W.B. (2008) Complexity of Service Value Networks Conceptualization and Empirical Investigation. IBM Systems Journal, 47, 53-68.

[3] Bishai, D., Paina, L., Li, Q., Peters, H.D., Hyder, A. (2014). Advancing the application of Systems Thinking in health: why cure crowds out prevention. Health Research Policy and Systems, 12(28)

[4] Blomqvist, J. (2007). Towards better addiction care? Prerequisites and consequences of the quest for evidence-based care. Social Services of Stockhom, County council of Stockholm, and others

[5] Cameron D. Norman, C.D., Charnaw-Burger, J., Yip, A.L., Saad, S., \& Lombardo, C. (2010). Designing health innovation networks using complexity science and Systems Thinking: the CoNEKTR model. Journal of Evaluation in Clinical Practice, Vol.16

[6] Carey, G., Malbon, E., Carey, N., Joyce, A., Crammond, B., \& Carey, A. (2015). Systems science and Systems Thinking for public health: a systematic review of the field. BMJ Open 2015;5: e009002. doi:10.1136/bmjopen-2015009002

[7] Durham, J., Schubert, L., Vaughan, L., \& Willis, C.D. (2018). Using Systems Thinking and the Intervention Level Framework to analyze public health planning for complex problems: Otitis media in Aboriginal and Torres Strait Islander children. PLoS ONE 13(3): e0194275.https://doi.org/ 10.1371/journal.pone.0194275

[8] https://www.who.int/health-topics/primary-health-care\#tab=tab_1.

[9] Hernández, A., Ruano, L.A., Marchal, B., Sebastián, S.M. \& Flores, W. (2017). Engaging with complexity to improve the health of indigenous people: a call for the use of Systems Thinking to tackle health inequity. International Journal for Equity in Health, 16(26).

[10] Homer, J.B \& Hirsch, B.G. (2006). System Dynamics Modeling for Public Health: Background and Opportunities. American Journal of Public Health, 96(3).

[11] Martinez- Garcia, M.A. (2013). Effect of CPAP on blood pressure in patients with obstructive sleep apnea and resistant hypertension: the HIPARCO randomized clinical trial. US National Library of Medicine.

[12] Mutale, W., Ayles, H., Bond, V., Chintu, N., Chilengi, R., Mwanamwenge, M.T., Taylor, A., Spicer, N., \& Balabanova, D. (2015). Application of Systems Thinking: 12-month postintervention evaluation of a complex health system intervention in Zambia: the case of the BHOMA. Journal of Evaluation in Clinical Practice

[13] National Bureau of Statistics (NBS) and United Nations children's Fund (UNICEF). 2017 Multiple Indicator Cluster Survey 2016-17, Survey Findings Report. Abuja, Nigeria: National Bureau of Statistics and United Nations children's Fund.

[14] National Population Commission (NPC) (Nigeria) and ICF International. 2014. Nigeria Demographic and Health Survey 2013. Abuja, Nigeria, and Rockville, Maryland, USA: NPC and ICF International.

[15] Peters, H.D. (2014). The application of Systems Thinking in health: why use Systems Thinking. Health Research Policy and Systems, 12(51).

[16] Roux, A.V. (2011). Complex Systems Thinking and Current Impasses in Health Disparities Research. American Journal of Public Health, 101(9)

[17] Rwashana, A.S., Nakubulwa, S., Nakakeeto-Kijjambu, M., \& Adam, T. (2014). Advancing the application of Systems Thinking in health: Understanding the dynamics of neonatal mortality in Uganda. Health research policy and systems, 12(36).

[18] Sarriot, G.E., Kauletio, M., Jahan, S., Rasul, I., \& Musha, A. (2014). Advancing the application of Systems Thinking in health: sustainability evaluation as learning and sense-making in a complex urban health system in Northern Bangladesh. Health Research Policy and Systems, 12(45).

[19] Senge, P. (1990). The Fifth Discipline: The Art and Practice of the Learning Organization

[20] Sharma, S.R \& Matheson, A. (2016). Systems Thinking in 21st century: a call to health promoters. Journal of public health, 15(2).

[21] Varghese, J., Kutty, R.V., Paina, L. \& Adam, T. (2014). Advancing the application of Systems Thinking in health: understanding the growing complexity governing immunization services in Kerala, India. Health Research Policy and Systems, 12(47).

[22] WHO Fact Sheet (2019). Retrieved from https://www.who.int. on Ftriday, 8th March 2019: 14:21pm

[23] WHO Health topic on Health system (2019). Retrieved from www.google.com on Friday, 8th March 2019.

[24] Zaidi, S., Riaz, A. \& Memon, Z. (2015). Residual Barriers for Utilization of Maternal and Child Health Services: Community Perceptions from Rural Pakistan. Health research policy and systems, 4(9). 